\title{
Pouchitis in inflammatory bowel disease: a review of diagnosis, prognosis, and treatment
}

\author{
Shintaro Akiyama, Victoria Rai, David T. Rubin \\ Inflammatory Bowel Disease Center, The University of Chicago Medicine, Chicago, IL, USA
}

Patients with inflammatory bowel disease (IBD) occasionally need a restorative proctocolectomy with ileal pouch-anal anastomosis (IPAA) because of medically refractory colitis or dysplasia/cancer. However, pouchitis may develop in up to $70 \%$ of patients after this procedure and significantly impair quality of life, more so if the inflammation becomes a chronic condition. About $10 \%$ of patients with IBD who develop pouchitis require pouch excision, and several risk factors of the failure have been reported. A phenotype that has features similar to Crohn's disease may develop in a subset of ulcerative colitis patients following proctocolectomy with IPAA and is the most frequent reason for pouch failure. In this review, we discuss the diagnosis and prognosis of pouchitis, risk factors for pouchitis development, and treatment options for pouchitis, including the newer biological agents. (Intest Res 2021;19:1-11)

Key Words: Pouchitis; Pouch failure; Inflammatory bowel disease; Crohn disease; Colitis, ulcerative

\section{INTRODUCTION}

In patients with inflammatory bowel disease (IBD), surgical intervention is sometimes required due to medically refractory colitis or development of dysplasia/cancer. A restorative proctocolectomy with ileal pouch-anal anastomosis (IPAA) is a standard procedure for those with severe and refractory colitis. The 10-year colectomy rate of patients with ulcerative colitis (UC) was reported as approximately $10 \%$ to $30 \%$ in the Western world and less than $10 \%$ in Asia, ${ }^{1}$ and the incidence of colectomy has declined after the introduction of biological treatments. ${ }^{2}$ However, inflammation of this reservoir ("pouchitis") can develop in up to $70 \%$ of patients after the surgery, and the incidence of pouch failure requiring diversion ileostomy or pouch excision was reported in up to $10 \%{ }^{3.5}$ Furthermore, even in patients originally diagnosed with UC, $10 \%$ of

Received May 5, 2020. Revised June 12, 2020. Accepted June 18, 2020. Correspondence to David T. Rubin, Inflammatory Bowel Disease Center, Department of Medicine, The University of Chicago Medicine, $5841 \mathrm{~S}$. Maryland Ave. MC 4076, Chicago, IL 60637, USA. Tel: +1-773-702-2950, Fax:+1-773-702-2182, E-mail: drubin@medicine.bsd.uchicago.edu patients can be diagnosed with Crohn's disease (CD) of the pouch. ${ }^{6}$

In this review, we discuss the diagnosis and prognosis of pouchitis, risk factors for pouchitis development, and treatment options for pouchitis, including the newer biological agents.

\section{CLINICAL COURSE AND DIAGNOSIS OF POUCHITIS}

Pouchitis is classified as acute or chronic pouchitis. ${ }^{7}$ Acute pouchitis is defined as symptoms lasting less than 4 weeks and responding to 2-week courses of antibiotics. Chronic pouchitis is defined as having symptoms lasting longer than 4 weeks despite standard antibiotic courses and requiring chronic antibiotics or anti-inflammatory therapy. ${ }^{3}$ Approximately $10 \%$ to $15 \%$ of patients with acute pouchitis develop chronic pouchitis which has subgroups such as antibiotic-dependent and antibiotic-refractory pouchitis. ${ }^{7.8}$

The diagnosis of pouchitis is based on the combined assessment of symptoms, endoscopic, and histologic findings. 
Sandborn et al. ${ }^{9}$ proposed the pouchitis disease activity index (PDAI), consisting of not only the score of clinical symptoms, but also endoscopic and histological scores. A later study suggested that the omission of histological scores from PDAI (modified PDAI) can offer similar diagnostic accuracy when compared with the PDAI for patients with acute pouchitis. ${ }^{10}$ The most frequently reported symptoms of pouchitis are increased bowel movement frequency, urgency, abdominal cramping, and pelvic discomfort. ${ }^{10}$ However, these symptoms are not specific for pouchitis, as following conditions could share these symptoms: ${ }^{11}$ infections including cytomegalovirus (CMV) and Clostridioides difficile, pouch-outlet obstruction, anal sphincter or pelvic floor dysfunction, decreased pouch compliance or emptying, pouch or anastomotic stricture, CD of the pouch, ${ }^{12}$ immune-mediated pouchitis, ${ }^{13}$ cuffitis, ${ }^{14}$ irritable pouch syndrome, ${ }^{15}$ and small intestinal bacterial overgrowth. ${ }^{14,16}$ To rule out other differential diagnoses as described above, serum or stool tests, imaging studies, and functional tests should be considered. Serum or tissue CMV polymerase chain reaction and stool tests including $C$. difficile toxins assay are helpful to exclude infections. Contrast X-ray of the pouch ("pouchogram") are useful to assess pouch compliance, emptying, strictures, and fistulas. Pelvic magnetic resonance imaging should be performed if fistulas would be suspected. When fecal incontinence is the primary symptom, especially in the absence of pouch inflammation, anorectal manometry and/or anal ultrasound are indicated to diagnose anal sphinc- ter or pelvic floor dysfunction. ${ }^{12}$ A subgroup of patients with pouchitis has concurrent immune-mediated conditions including primary sclerosing cholangitis (PSC), seropositivity for immunoglobulin G4 (IgG4) or perinuclear antineutrophil cytoplasmic antibody (pANCA), and infiltration of IgG4-expressing plasma cells in the pouch mucosa. ${ }^{13}$ Hence, serum markers of autoimmune diseases including IgG4 or pANCA might be beneficial to identify underlying autoimmunity in patients with pouchitis. If all these tests including pouchoscopy are negative, irritable pouch syndrome or small intestinal bacterial overgrowth would be considered.

Diagnostic strategy for pouchitis is described in Fig. 1. If patients with proctocolectomy and IPAA have symptoms suggestive of pouchitis, pouchoscopy should be recommended. Although there are no standard strategies of proactive monitoring for asymptomatic patients with IBD, postoperative pouchoscopy is suggested based on findings from a study showing that approximately $50 \%$ of asymptomatic UC patients have abnormal endoscopic pouch findings. ${ }^{17} \mathrm{~A}$ recent study also showed that mucosal breaks including ulcers and/ or erosions were observed in about $20 \%$ of asymptomatic patients and were associated with an increased risk of acute pouchitis. ${ }^{18}$ Hence, pouchoscopy is an essential procedure to confirm the diagnosis of pouchitis.

During pouchoscopy, it is important for providers to define the endoscopic phenotype of the J pouch based on the observation of different anatomic areas of the J pouch: the afferent

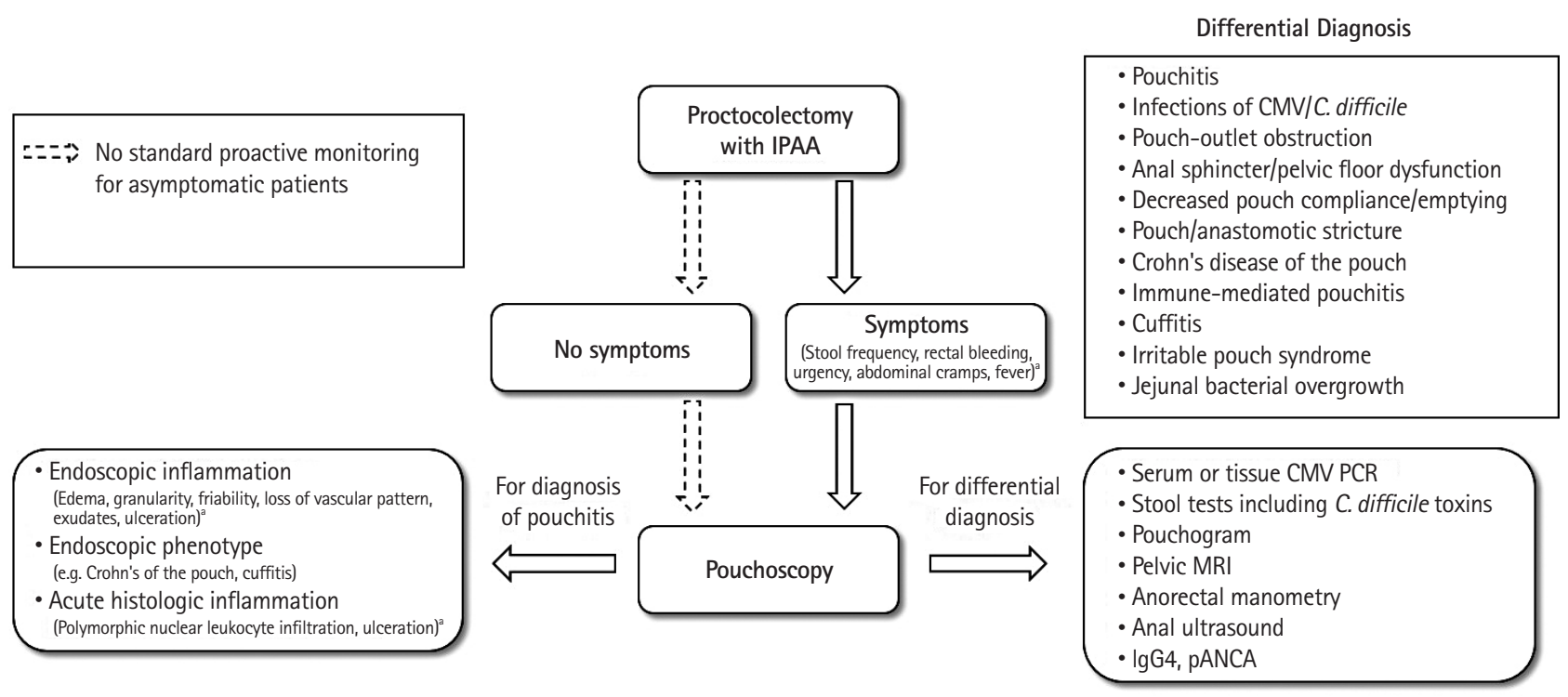

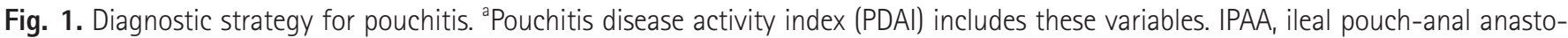
mosis; CMV, cytomegalovirus; C. difficile, Clostridioides difficile; PCR, polymerase chain reaction; MRI, magnetic resonance imaging; IgG4, immunoglobulin G4, pANCA, perinuclear antineutrophil cytoplasmic antibody. 
limb, inlet, tip of the J, proximal and distal pouch, anastomosis, rectal cuff, anal canal, and perianal area (Fig. 2). For instance, in patients with $\mathrm{CD}$ of the pouch, the afferent limb would have endoscopic inflammation including stricture or the perianal area might have fistula. Such phenotype would have a high risk of pouch removal ${ }^{6}$ and intensive treatment with careful monitoring are required to improve its prognosis. Persistent inflammation in a strip of rectal cuff is also a major complication in IBD patients treated by proctocolectomy with IPAA and cuff biopsies are helpful to diagnose cuffitis. ${ }^{12}$

Furthermore, pouchoscopy with biopsy focusing on the rectal cuff should be recommended in patients with preoperative neoplasia of the colon and/or rectum. Although there are no consensus guidelines for endoscopic surveillance for pouch neoplasia, patients undergo surveillance pouchoscopy every $1-3$ years at the discretion of the IBD specialists in some institutions. ${ }^{19}$ There is an unmet need to investigate whether endoscopic activity of pouchitis may be a "target to treat" even in asymptomatic patients and which endoscopic phenotypes of

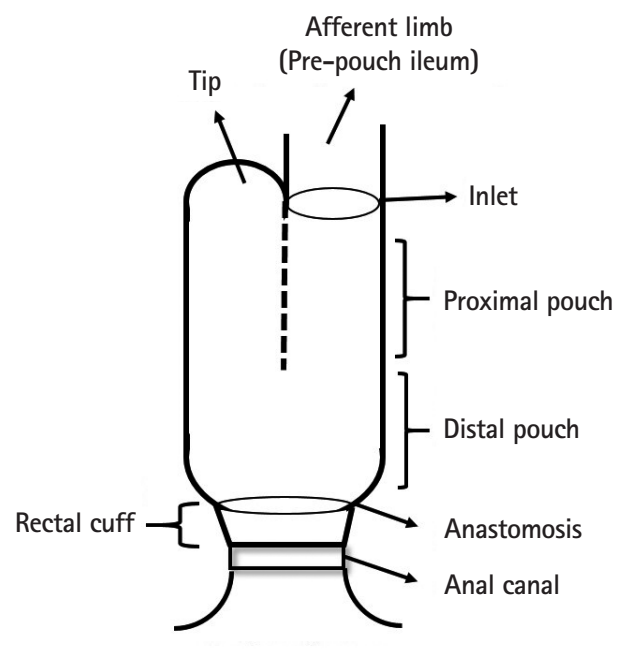

Perianal area

Fig. 2. Schema of the J pouch. the J pouch can affect the prognosis. The standard proactive monitoring of pouch inflammation and surveillance of pouch neoplasia must be established for IBD patients after proctocolectomy with IPAA.

The rate of pouch failure requiring diversion ileostomy or pouch excision has been reported to be as high as $10 \%^{3-5}$ and several risk factors contributing to the failure have been reported (Table 1). Manilich et al. ${ }^{4}$ identified 4 factors that contributed to pouch failure at the Cleveland Clinic (Cleveland, OH, USA): (1) completion proctocolectomy, (2) handsewn anastomosis, (3) CD diagnosis on postoperative histopathology, and (4) diabetes. However, a multicenter cohort analysis of these factors did not show the suitable performance for clinical practice. ${ }^{20}$ This validation study showed that only handsewn anastomosis contributed to pouch survival and found ileo-anal anastomotic leakage and CD of the pouch, which were not included in the Cleveland Clinic study, were strongly associated with pouch failure. ${ }^{20}$

Pelvic sepsis including anastomotic leakage, abscess, and fistula can be developed in up to $20 \%$ of UC patients treated by proctocolectomy with IPAA. ${ }^{21,22}$ Fazio et al. ${ }^{23}$ described pelvic sepsis as an independent risk factor of pouch failure. Previous studies demonstrated that the rate of anastomotic leak ${ }^{24}$ or abscess ${ }^{25}$ in patients with handsewn anastomoses was significantly higher than those with stapled anastomosis. However, a meta-analysis did not show any significant difference in the rate of pelvic sepsis, anastomotic leak, and pouch-related fistula between the 2 groups. ${ }^{26}$

CD of the pouch can develop in a subset of UC patients treated by proctocolectomy with IPAA and is the most frequent reason for pouch failure and excision. ${ }^{27} \mathrm{~A}$ recent metaanalysis showed that, among 4,843 patients with an IPAA for UC or indeterminate colitis, $10.3 \%$ of patients were diagnosed with $\mathrm{CD}$ of the pouch. ${ }^{6}$ Although a uniform definition of $\mathrm{CD}$ of the pouch is still lacking, ${ }^{27}$ the most commonly reported diagnostic criteria were (1) presence of fistula/fistulae, (2) stricture

Table 1. Predictive Factors of Pouch Failure

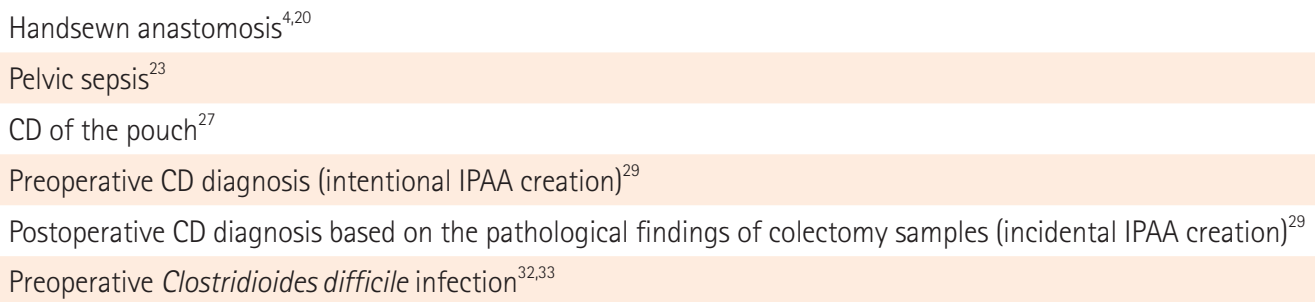

$\mathrm{CD}$, Crohn's disease; IPAA, ileal pouch-anal anastomosis. 
involving the pouch or pre-pouch ileum, and (3) presence of pre-pouch ileitis. ${ }^{6}$ Shen et al. ${ }^{28}$ demonstrated that $16 \%$ of patients with $\mathrm{CD}$ of the pouch developed pouch failure in a median of 6 years after ileostomy takedown. Patients diagnosed with CD before colectomy (intentional IPAA) and those with UC or indeterminate colitis whose diagnosis was revised to CD based on the pathological findings of colectomy specimens (incidental IPAA) have a risk of pouch failure. ${ }^{29} \mathrm{~A}$ recent meta-analysis showed that the pouch failure rate in $\mathrm{CD}$ patients with intentional and incidental IPAA was significantly higher compared to UC (odds ratio [OR], 2.48; 95\% confidence interval [CI], 1.25-4.92 and OR, 8.53; 95\% CI, 3.21-22.66, respectively). ${ }^{29}$

C. difficile infection is the most common nosocomial pathogen responsible for severe colitis and frequently complicated with IBD. ${ }^{30,31}$ Previous studies found that $C$. difficile infection before colectomy does not increase the risk of the development of pouchitis but can be associated with poor pouch outcomes. ${ }^{32,33}$ Lightner et al. ${ }^{32}$ showed that the rate of pouchitis was not significantly different between UC patients with preoperative C. difficile infection and those without. However, patients with pouchitis who had been exposed to $C$. difficile infection prior to colectomy were more likely to require anti- tumor necrosis factor (TNF) drugs and diverting ileostomy, and pouch excision. ${ }^{33}$

\section{RISK FACTORS FOR THE DEVELOPMENT OF POUCHITIS}

Previous studies have reported factors contributing to the development of pouchitis ${ }^{7}$ (Table 2). Extraintestinal manifestations of IBD are associated with increased likelihood of the development of chronic pouchitis. ${ }^{34,35}$ About $2 \%$ to $7.5 \%$ of patients with UC may have co-existent PSC, a chronic cholestatic syndrome of unknown cause characterized by fibrosing obliteration of the bile ducts. ${ }^{36-38}$ The presence of PSC increases the risk of acute and chronic pouchitis and is an independent risk factor for the development of pouchitis. ${ }^{39-42}$ The cumulative risk of pouchitis at 10 years after IPAA was $79 \%$ for UC patients with PSC and $46 \%$ for those without. ${ }^{41}$ Backwash ileitis, which is frequently observed in UC patients with PSC, $^{38}$ is reported as a considerable risk of developing chronic pouchitis. ${ }^{39}$ A later prospective study showed the incidence of acute or chronic pouchitis did not differ significantly between patients with backwash ileitis and those without. ${ }^{43,44}$ The relationship between backwash ileitis and the development of pou-

Table 2. Factors Related to the Development of Pouchitis

\begin{tabular}{|c|c|}
\hline Factors & Comments \\
\hline Primary sclerosing cholangitis (PSC) ${ }^{41,42}$ & PSC increases the risk of acute and chronic pouchitis. ${ }^{41,42}$ \\
\hline Backwash ileitis ${ }^{39,43}$ & $\begin{array}{l}\text { Backwash ileitis was reported as a considerable risk of developing chronic pouchitis. }{ }^{39} \mathrm{~A} \text { later } \\
\text { prospective study showed the incidence of acute or chronic pouchitis did not differ significantly } \\
\text { between patients with backwash ileitis and those without. }{ }^{43}\end{array}$ \\
\hline Smoking ${ }^{35,47,48}$ & $\begin{array}{l}\text { A retrospective study showed that smoking cessation may increase the risk of pouchitis. }{ }^{47} \\
\text { A prospective study has demonstrated that current or prior history of smoking can increase the } \\
\text { risk of acute pouchitis but be protective against the development of chronic pouchitis. } \\
\text { A meta-analysis showed the odds of pouchitis development was not significantly lower in } \\
\text { smokers compared with non-smokers. }{ }^{38}\end{array}$ \\
\hline Extensive colitis $^{44,49}$ & $\begin{array}{l}\text { Pancolitis was reported to be directly related to the development of chronic pouchitis. }{ }^{44} \text { Case- } \\
\text { control studies showed extesive colonic disease was associated with increased risk for both acute } \\
\text { and chronic pouchitis. }{ }^{49}\end{array}$ \\
\hline Male sex ${ }^{50,51}$ & Male patients were found to have an increased risk for chronic pouchitis. ${ }^{50,51}$ \\
\hline Antineutrophil cytoplasmic antibody (ANCA) $)^{52}$ & $\begin{array}{l}\text { A meta-analysis showed the risk of chronic pouchitis was higher in ANCA-positive patients, but } \\
\text { the risk of acute pouchitis was unaffected by ANCA status. }{ }^{52}\end{array}$ \\
\hline Histologic findings of colectomy samples ${ }^{53}$ & $\begin{array}{l}\text { The combination of the degree of mononuclear cell infiltration (MNCI), segmental distribution } \\
\text { of } \mathrm{MNCl} \text {, and eosinophil infiltration in the resected total colon had a utility to predict the } \\
\text { development of chronic pouchitis. }\end{array}$ \\
\hline 3-Stage ileal pouch-anal anastomosis (IPAA) $)^{54}$ & $\begin{array}{l}\text { A multicenter, retrospective cohort study of pouchitis in pediatric ulcerative colitis showed that } \\
\text { 3-stage IPAA may increase the risk of pouchitis. }{ }^{54}\end{array}$ \\
\hline Nonsteroidal anti-inflammatory drugs (NSAIDs) $)^{46,49}$ & $\begin{array}{l}\text { NSAIDs was reported to increase the risk of pouchitis. }{ }^{46} \text { Case-control studies showed postoperative } \\
\text { use of NSAIDs was a risk factor for chronic pouchitis and possibly for acute pouchitis. }{ }^{49}\end{array}$ \\
\hline
\end{tabular}


chitis is still unclear.

Tobacco smoking was previously reported as a preventive factor for pouchitis but this is not well established. ${ }^{45,46} \mathrm{~A}$ recent retrospective study showed that smoking cessation may increase the risk of pouchitis although active smoking does not seem to be preventive for pouchitis. ${ }^{47}$ On the other hand, a prospective study has demonstrated that current or prior history of smoking can increase the risk of acute pouchitis but be protective against the development of chronic pouchitis. ${ }^{35}$ A metaanalysis showed the odds of pouchitis development was not significantly lower in smokers compared with non-smokers (OR, 0.57; 95\% CI, 0.21-1.53). ${ }^{48}$ This meta-analysis did not differentiate between studies of acute and chronic pouchitis and further studies are necessary to understand the different effects of smoking on the development of acute and chronic pouchitis.

Extensive colitis, ${ }^{44,49}$ male sex, ${ }^{50,51}$ ANCA (antineutrophil cytoplasmic antibody), ${ }^{52}$ histologic findings of colectomy samples, ${ }^{53} 3$-stage IPAA, ${ }^{54}$ and nonsteroidal anti-inflammatory $\operatorname{drugg}^{46,49}$ are other possible risk factors of pouchitis (Table 2).

\section{TREATMENT OF POUCHITIS}

\section{Acute Pouchitis}

The mainstay of the treatment for acute pouchitis was antibiotics, including ciprofloxacin, metronidazole, or rifaximin.$^{55-57}$ A small randomized controlled study found that ciprofloxacin achieved a greater reduction in the PDAI and was better tolerated than metronidazole. ${ }^{58}$ Rifaximin was not more effective than placebo. ${ }^{56}$ Hence, ciprofloxacin is recommended as firstline treatment (Table 3, Fig. 3). The concentrated probiotic mixture VSL\#3 was also reported to prevent acute pouchitis developed within the first year after surgery. A double-blind, placebo-controlled study showed that patients treated with VSL\#3 had a significantly lower incidence of acute pouchitis (10\%) compared with those with placebo (40\%). ${ }^{59}$

\section{Chronic Pouchitis}

To treat chronic pouchitis, a combination of oral antibiotics, ${ }^{60,61}$ budesonide, ${ }^{62}$ topical tacrolimus, ${ }^{63}$ or beclomethasone dipropionate $^{64}$ are available (Table 3, Fig. 3). Once in remission from chronic pouchitis, VSL\#3 can help to maintain remission. Two double-blind, placebo-controlled studies have demonstrated that VSL\#3 is effective to maintain remission after induction with combination antibiotic therapies. ${ }^{65,66}$

If a combination of oral antibiotics fail to induce or maintain remission, oral or topical mesalamine, corticosteroids, ${ }^{67}$ anti-
TNF drugs including infliximab ${ }^{68-71}$ and adalimumab $b^{72,73}$ are shown to be effective for chronic pouchitis. ${ }^{747}$ According to a recent meta-analysis regarding the efficacy of anti-TNF therapy on chronic refractory pouchitis, the rates of short-term (8 weeks) and long-term (12 months) clinical remission were 0.10 (95\% CI, $0.00-0.35$ ) and 0.37 (95\% CI, 0.14-0.62), respectively. ${ }^{76}$

Vedolizumab, a novel humanized IgG1 monoclonal antibody against $\alpha_{4} \beta_{7}$ integrin, can be safe and effective in the management of chronic pouchitis. Vedolizumab acts by suppressing intestinal inflammation through inhibition of leukocyte trafficking to the digestive tract. ${ }^{77} \mathrm{~A}$ retrospective, multicenter study on the efficacy of vedolizumab in chronic, antibiotic-dependent or refractory pouchitis showed the remarkable reduction in the PDAI after 14 weeks of vedolizumab therapy without any serious side effects. ${ }^{78}$ Another study demonstrated that the rate of patients with chronic pouchitis who achieved a clinical response at 12 months after starting vedolizumab was $39.1 \%$. Meanwhile, the rate of endoscopic response at 6 months was $58.3 \%$ in chronic pouchitis. ${ }^{79}$

Ustekinumab is a human IgG1 kappa monoclonal antibody against the p40 subunit of interleukin- $12 / 23{ }^{80}$ This drug has been used as the treatment of moderately to severely active $\mathrm{CD}$ and was recently approved for moderately to severely active UC. ${ }^{81}$ A retrospective study at the University of Chicago demonstrated improvements in clinical symptoms such as bowel movements and endoscopic subscore of the PDAI after 1 year of ustekinumab therapy. ${ }^{82}$ Larger prospective studies are needed to confirm the efficacy of vedolizumab and ustekinumab for chronic pouchitis (Table 3, Fig. 3).

In terms of $\mathrm{CD}$ of the pouch, there is no standard guideline regarding its treatment. ${ }^{27}$ The treatment includes antibiotics, 5-aminosalicylic acid products, corticosteroids, immunomodulators, and biologics and the efficacy of these treatments remains inconsistent across studies. ${ }^{27} \mathrm{~A}$ recent meta-analysis evaluated the efficacy of anti-TNF therapy in distinguishing patients with chronic antibiotic-refractory pouchitis from those with $\mathrm{CD}$ of the pouch. In this study, $\mathrm{CD}$ of the pouch was defined as the presence of non-anastomotic fistula and/or stenosis and/or significant pre-pouch ileitis. ${ }^{76}$ Anti-TNF therapy had higher and faster efficacy in patients with $\mathrm{CD}$ of the pouch compared with chronic antibiotic-refractory pouchitis. The rate of short-term (8 weeks) and long-term (12 months) clinical remission in CD of the pouch were 0.64 (95\% CI, 0.5-0.77) and 0.57 (95\% CI, 0.43-0.71), respectively. ${ }^{70,76,83}$

Vedolizumab and ustekinumab can be effective therapy for $\mathrm{CD}$ of the pouch. ${ }^{84} \mathrm{~A}$ retrospective multicenter study of vedoli- 
Table 3. Treatments of Pouchitis

\begin{tabular}{|c|c|c|c|c|}
\hline Treatment type & $\begin{array}{l}\text { Pouch } \\
\text { condition }\end{array}$ & $\begin{array}{l}\text { Response or } \\
\text { remission rate/ } \\
\text { duration of } \\
\text { treatment }\end{array}$ & Primary outcome & Dose \\
\hline $\begin{array}{l}\text { Oral antibiotics } \\
\text { (ciprofloxacin or } \\
\text { metronidazole) }^{55}\end{array}$ & $\begin{array}{l}\text { Acute } \\
\text { pouchitis }\end{array}$ & $\begin{array}{l}\text { 96\%/ } \\
\text { up to } 14 \text { days }\end{array}$ & $\begin{array}{l}\text { Response to oral antibiotics determined by } \\
\text { resolution of symptoms. }\end{array}$ & $\begin{array}{l}\text { Metronidazole } 250 \text { mg three times } \\
\text { daily for } 7 \text { days. Metronidazole was } \\
\text { switched to ciprofloxacin } 500 \text { mg } \\
\text { twice a day for } 7 \text { days if patients failed } \\
\text { metronidazole or had its side effects. }\end{array}$ \\
\hline $\begin{array}{l}\text { Oral antibiotics } \\
\text { (ciprofloxacin and } \\
\text { metronidazole) }^{60}\end{array}$ & $\begin{array}{l}\text { Chronic } \\
\text { pouchitis }\end{array}$ & $82 \% / 28$ days & $\begin{array}{l}\text { Remission defined as a combination of PDAl } \\
\text { clinical score of } \leq 2 \text {, endoscopic score of } \\
\leq 1 \text { and total score of } \leq 4 \text {. }\end{array}$ & $\begin{array}{l}\text { A combination of metronidazole } 400 \text { or } \\
500 \mathrm{mg} \text { twice daily, and ciprofloxacin } \\
500 \mathrm{mg} \text { twice daily for } 28 \text { days }\end{array}$ \\
\hline Oral budesonide ${ }^{62}$ & $\begin{array}{l}\text { Chronic } \\
\text { pouchitis }\end{array}$ & 75\%/8 weeks & $\begin{array}{l}\text { Remission defined as a combination of PDAl } \\
\text { clinical score of } \leq 2 \text {, endoscopic score of } \\
\leq 1 \text { and total score of } \leq 4 \text {. }\end{array}$ & $9 \mathrm{mg} /$ day for 8 weeks \\
\hline$V$ edolizumab ${ }^{79}$ & $\begin{array}{l}\text { Chronic } \\
\text { pouchitis }\end{array}$ & $\begin{array}{l}\text { 40.7\%/3 months } \\
39.1 \% / 12 \text { months }\end{array}$ & $\begin{array}{l}\text { Clinical response defined as any improvement } \\
\text { in symptoms including a decrease in bowel } \\
\text { movements, pain, or fistula drainage. }\end{array}$ & $\begin{array}{l}300 \mathrm{mg} \text { at weeks } 0,2,6 \text {, then every } 4-8 \\
\text { weeks }\end{array}$ \\
\hline Ustekinumab $^{82}$ & $\begin{array}{l}\text { Chronic } \\
\text { pouchitis }\end{array}$ & $\begin{array}{l}\text { 50\%/12.9 months } \\
\text { (median) }\end{array}$ & $\begin{array}{l}\text { Clinical response defined as any improvement in } \\
\text { physician global assessment and the number } \\
\text { of bowel movements per } 24 \text { hours. }\end{array}$ & $\begin{array}{l}\text { One } 90 \text { mg IV loading dose infusion } \\
\text { followed by } 90 \text { mg injections every } 8 \\
\text { weeks }\end{array}$ \\
\hline Infliximab ${ }^{83}$ & $\begin{array}{l}\text { CD of } \\
\text { the pouch }\end{array}$ & $\begin{array}{l}\text { Short term } \\
84.6 \% \%^{\mathrm{a}} / 8 \text { weeks } \\
\text { Long term } \\
54.2 \% \%^{\mathrm{a}} / 21.5 \text { months } \\
\text { (median) }\end{array}$ & $\begin{array}{l}\text { Short term CR defined as cessation of fistula } \\
\text { drainage and total closure of all fistulas, } \\
\text { or cessation of diarrhea, incontinence, and } \\
\text { abdominal pain. Short term PR defined } \\
\text { as a reduction in number, size, drainage, } \\
\text { or discomfort associated with fistulas, or } \\
\text { decrease of diarrhea and abdominal pain. Long } \\
\text { term CR defined as maintenance of remission. } \\
\text { Long term PR defined as maintenance of a } \\
\text { partial clinical improvement. }\end{array}$ & $\begin{array}{l}5 \mathrm{mg} / \mathrm{kg} \text { at weeks } 0,2,6 \text {, then every } 8 \\
\text { weeks }\end{array}$ \\
\hline Ustekinumab $^{85}$ & $\begin{array}{l}\text { CD of } \\
\text { the pouch }\end{array}$ & 83\%/6 months & $\begin{array}{l}\text { Clinical response defined as any improvement } \\
\text { in symptoms including a decrease in bowel } \\
\text { movements, pain, or fistula drainage. }\end{array}$ & $\begin{array}{l}\text { Weight-based IV infusion, then } 90 \text { mg } \\
\text { injections every } 8 \text { weeks }\end{array}$ \\
\hline
\end{tabular}

${ }^{a}$ The rate of patients who experienced $C R$ and $P R$.

$P D A l$, pouchitis disease activity index; PR, partial response; $C D$, Crohn's disease; $C R$, complete response; IV, intravenous.

zumab demonstrated that the proportion of patients with $\mathrm{CD}$ of the pouch who achieved a clinical response was $48.9 \%$ at 12 months after starting vedolizumab. The proportion of endoscopic response at 6 months was $53.6 \%$ in $\mathrm{CD}$ of the pouch. ${ }^{79}$ For ustekinumab, a retrospective multicenter study found that the rate of clinical and endoscopic response 6 months after ustekinumab induction was $83 \%$ and $60 \%$, respectively (Table 3, Fig. 3$)^{85}$

\section{SUMMARY AND FUTURE DIRECTIONS}

Pouchitis can frequently develop in patients with IBD after creation of an IPAA and significantly impair quality of life. In this article, we reviewed the diagnosis, prognosis, and treatment of pouchitis in IBD patients.

However, much remains uncertain in our clinical intervention of pouchitis in patients with IBD. Studies to improve 


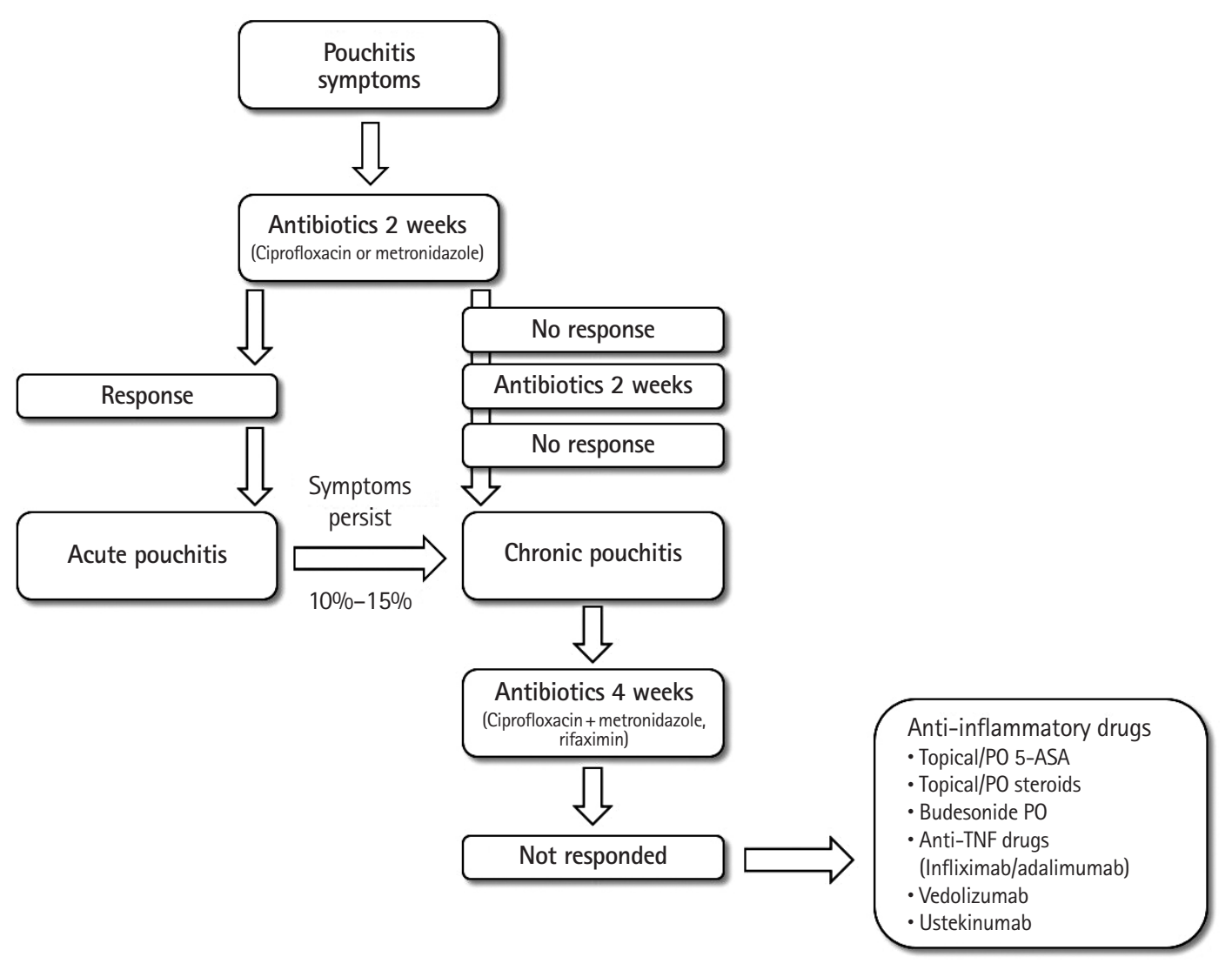

Fig. 3. Treatment strategy for pouchitis. PO, per os; 5-ASA, 5-aminosalicylic acid; TNF, tumor necrosis factor.

pouch outcomes are essential and, as presented in this review, could begin with investigating a proactive monitoring protocol. Since the pouch inflammation can be identified by pouchoscopy even in asymptomatic patients, we need to investigate endoscopic activity as a proactive target to treat pouchitis. Furthermore, though previous studies demonstrated that $\mathrm{CD}$ of the pouch is a poor prognostic factor in IBD patients, the definition of $\mathrm{CD}$ of the pouch is still controversial and further studies should be warranted to characterize this phenotype. The detailed assessment of endoscopic findings in each anatomical area of the J pouch would be helpful to understand which endoscopic phenotypes may be associated with the J pouch prognosis. Such an analysis may provide meaningful information to clarify which endoscopic findings should be a target to improve outcomes. Endoscopic phenotyping of the J pouch might also be useful for future research to understand the pathogenesis of heterogeneous types of pouchitis in IBD patients, which in turn may improve therapeutic options. ${ }^{86}$

Overall, our experiences with pouchitis-its diagnosis, prognosis, and treatment-are growing and so should our efforts to standardize screening protocols, classification, and treatment of this type of IBD.

\section{ADDITIONAL INFORMATION}

\section{Funding Source}

The authors received no financial support for the research, authorship, and/or publication of this article.

\section{Conflict of Interest}

Rubin DT has received grant support from Takeda, and has served as a consultant for Abbvie, Abgenomics, Allergan Inc., Boehringer Ingelheim Ltd., Bristol-Myers Squibb, Celgene Corp/Syneos, Check-cap, Dizal Pharmaceuticals, GalenPharma/Atlantica, Genentech/Roche, Gilead Sciences, Ichnos Sciences S.A., GlaxoSmithKline Services, Janssen Pharmaceuticals, Lilly, Narrow River Mgmt, Pfizer, Prometheus Laboratories, Reistone, Shire, Takeda, and Techlab Inc. Akiyama S and Rai $V$ report no conflicts of interest.

Rubin DT is an editorial board member of the journal but did not involve in the peer reviewer selection, evaluation, or 
decision process of this article. No other potential conflicts of interest relevant to this article were reported.

\section{Author Contribution}

Conceptualization: Akiyama S, Rubin DT. Investigation: Akiyama S, Rai V. Supervision: Rubin DT. Writing - original draft: Akiyama S. Writing - review \& editing: Akiyama S, Rai V, Rubin DT. Approval of final manuscript: all authors.

\section{ORCID}

Akiyama S

Rai $\mathrm{V}$

Rubin DT

\section{REFERENCES}

1. Bernstein CN, Ng SC, Lakatos PL, Moum B, Loftus EV Jr; Epidemiology and Natural History Task Force of the International Organization of the Study of Inflammatory Bowel Disease. A review of mortality and surgery in ulcerative colitis: milestones of the seriousness of the disease. Inflamm Bowel Dis 2013;19:2001-2010.

2. Abou Khalil M, Boutros M, Nedjar H, et al. Incidence rates and predictors of colectomy for ulcerative colitis in the era of biologics: results from a provincial database. J Gastrointest Surg 2018;22:124-132.

3. Fazio VW, Kiran RP, Remzi FH, et al. Ileal pouch anal anastomosis: analysis of outcome and quality of life in 3707 patients. Ann Surg 2013;257:679-685.

4. Manilich E, Remzi FH, Fazio VW, Church JM, Kiran RP. Prognostic modeling of preoperative risk factors of pouch failure. Dis Colon Rectum 2012;55:393-399.

5. Tekkis PP, Lovegrove RE, Tilney HS, et al. Long-term failure and function after restorative proctocolectomy: a multi-centre study of patients from the UK National Ileal Pouch Registry. Colorectal Dis 2010;12:433-441.

6. Barnes EL, Kochar B, Jessup HR, Herfarth HH. The incidence and definition of Crohn's disease of the pouch: a systematic review and meta-analysis. Inflamm Bowel Dis 2019;25:14741480.

7. Hata K, Ishihara S, Nozawa H, et al. Pouchitis after ileal pouchanal anastomosis in ulcerative colitis: diagnosis, management, risk factors, and incidence. Dig Endosc 2017;29:26-34.

8. Sandborn WJ. Pouchitis following ileal pouch-anal anastomosis: definition, pathogenesis, and treatment. Gastroenterology 1994;107:1856-1860.
9. Sandborn WJ, Tremaine WJ, Batts KP, Pemberton JH, Phillips SF. Pouchitis after ileal pouch-anal anastomosis: a pouchitis disease activity index. Mayo Clin Proc 1994;69:409-415.

10. Shen B, Achkar JP, Connor JT, et al. Modified pouchitis disease activity index: a simplified approach to the diagnosis of pouchitis. Dis Colon Rectum 2003;46:748-753.

11. Mignon M, Stettler C, Phillips SF. Pouchitis: a poorly understood entity. Dis Colon Rectum 1995;38:100-103.

12. Pardi DS, Sandborn WJ. Systematic review: the management of pouchitis. Aliment Pharmacol Ther 2006;23:1087-1096.

13. Seril DN, Yao Q, Shen B. The association between autoimmunity and pouchitis. Inflamm Bowel Dis 2014;20:378-388.

14. Shen B, Achkar JP, Lashner BA, et al. Endoscopic and histologic evaluation together with symptom assessment are required to diagnose pouchitis. Gastroenterology 2001;121:261-267.

15. Shen B, Achkar JP, Lashner BA, et al. Irritable pouch syndrome: a new category of diagnosis for symptomatic patients with ileal pouch-anal anastomosis. Am J Gastroenterol 2002; 97:972-977.

16. O'Connell PR, Rankin DR, Weiland LH, Kelly KA. Enteric bacteriology, absorption, morphology and emptying after ileal pouch-anal anastomosis. Br J Surg 1986;73:909-914.

17. Zhu H, Wu XR, Queener E, Kiran RP, Remzi FH, Shen B. Clinical value of surveillance pouchoscopy in asymptomatic ileal pouch patients with underlying inflammatory bowel disease. Surg Endosc 2013;27:4325-4332.

18. Kayal M, Plietz M, Radcliffe M, et al. Endoscopic activity in asymptomatic patients with an ileal pouch is associated with an increased risk of pouchitis. Aliment Pharmacol Ther 2019;50: 1189-1194

19. Khan F, Shen B. Inflammation and neoplasia of the pouch in inflammatory bowel disease. Curr Gastroenterol Rep 2019;21:10.

20. Sahami S, Bartels SA, D'Hoore A, et al. External validation of a prognostic model of preoperative risk factors for failure of restorative proctocolectomy. Colorectal Dis 2017;19:181-187.

21. de Zeeuw S, Ahmed Ali U, Donders RA, Hueting WE, Keus F, van Laarhoven CJ. Update of complications and functional outcome of the ileo-pouch anal anastomosis: overview of evidence and meta-analysis of 96 observational studies. Int J Colorectal Dis 2012;27:843-853.

22. Ide S, Araki T, Okita Y, et al. Outcome and functional prognosis of pelvic sepsis after ileal pouch-anal anastomosis in patients with ulcerative colitis. Surg Today 2017;47:301-306.

23. Fazio VW, Tekkis PP, Remzi F, et al. Quantification of risk for pouch failure after ileal pouch anal anastomosis surgery. Ann Surg 2003;238:605-614. 
24. Cohen Z, McLeod RS, Stephen W, Stern HS, O'Connor B, Reznick R. Continuing evolution of the pelvic pouch procedure. Ann Surg 1992;216:506-511.

25. Ziv Y, Fazio VW, Church JM, Lavery IC, King TM, Ambrosetti P. Stapled ileal pouch anal anastomoses are safer than handsewn anastomoses in patients with ulcerative colitis. Am J Surg 1996;171:320-323.

26. Lovegrove RE, Constantinides VA, Heriot AG, et al. A comparison of hand-sewn versus stapled ileal pouch anal anastomosis (IPAA) following proctocolectomy: a meta-analysis of 4183 patients. Ann Surg 2006;244:18-26.

27. Lightner AL, Pemberton JH, Loftus EJ Jr. Crohn's disease of the ileoanal pouch. Inflamm Bowel Dis 2016;22:1502-1508.

28. Shen B, Remzi FH, Brzezinski A, et al. Risk factors for pouch failure in patients with different phenotypes of Crohn's disease of the pouch. Inflamm Bowel Dis 2008;14:942-948.

29. Pellino G, Vinci D, Signoriello G, et al. Long-term bowel function and fate of the ileal pouch after restorative proctocolectomy in patients with Crohn's disease: a systematic review with meta-analysis and metaregression. J Crohns Colitis 2020;14: 418-427.

30. Magill SS, Edwards JR, Bamberg W, et al. Multistate pointprevalence survey of health care-associated infections. N Engl J Med 2014;370:1198-1208.

31. Razik R, Rumman A, Bahreini Z, McGeer A, Nguyen GC. Recurrence of Clostridium difficile infection in patients with inflammatory bowel disease: the recidivism study. Am J Gastroenterol 2016;111:1141-1146.

32. Lightner AL, Tse CS, Quinn K, et al. Preoperative Clostridium difficile infection does not affect pouch outcomes in patients with ulcerative colitis who undergo ileal pouch-anal anastomosis. Inflamm Bowel Dis 2017;23:1195-1201.

33. Skowron KB, Lapin B, Rubin M, et al. Clostridium difficile infection in ulcerative colitis: can alteration of the gut-associated microbiome contribute to pouch failure? Inflamm Bowel Dis 2016;22:902-911.

34. Hata K, Ishii H, Anzai H, et al. Preoperative extraintestinal manifestations associated with chronic pouchitis in Japanese patients with ulcerative colitis after ileal pouch-anal anastomosis: a retrospective study. Inflamm Bowel Dis 2017;23:10191024.

35. Fleshner P, Ippoliti A, Dubinsky M, et al. A prospective multivariate analysis of clinical factors associated with pouchitis after ileal pouch-anal anastomosis. Clin Gastroenterol Hepatol 2007;5:952-958.

36. LaRusso NF, Wiesner RH, Ludwig J, MacCarty RL. Current concepts. Primary sclerosing cholangitis. N Engl J Med 1984; 310:899-903.

37. Loftus EV Jr, Sandborn WJ, Lindor KD, Larusso NF. Interactions between chronic liver disease and inflammatory bowel disease. Inflamm Bowel Dis 1997;3:288-302.

38. Loftus EV Jr, Harewood GC, Loftus CG, et al. PSC-IBD: a unique form of inflammatory bowel disease associated with primary sclerosing cholangitis. Gut 2005;54:91-96.

39. Abdelrazeq AS, Kandiyil N, Botterill ID, et al. Predictors for acute and chronic pouchitis following restorative proctocolectomy for ulcerative colitis. Colorectal Dis 2008;10:805-813.

40. Pavlides M, Cleland J, Rahman M, et al. Outcomes after ileal pouch anal anastomosis in patients with primary sclerosing cholangitis. J Crohns Colitis 2014;8:662-670.

41. Penna C, Dozois R, Tremaine W, et al. Pouchitis after ileal pouch-anal anastomosis for ulcerative colitis occurs with increased frequency in patients with associated primary sclerosing cholangitis. Gut 1996;38:234-239.

42. Tenca A, Jaakkola T, Färkkilä M, Arola J, Kolho KL. Impact of paediatric onset primary sclerosing cholangitis on clinical course and outcome of inflammatory bowel disease: a casecontrol population-based study in Finland. Scand J Gastroenterol 2019;54:984-990.

43. White E, Melmed GY, Vasiliauskas EA, et al. A prospective analysis of clinical variables, serologic factors, and outcome of ileal pouch-anal anastomosis in patients with backwash ileitis. Dis Colon Rectum 2010;53:987-994.

44. Hashavia E, Dotan I, Rabau M, Klausner JM, Halpern Z, Tulchinsky H. Risk factors for chronic pouchitis after ileal pouch-anal anastomosis: a prospective cohort study. Colorectal Dis 2012;14:1365-1371.

45. Merrett MN, Mortensen N, Kettlewell M, Jewell DO. Smoking may prevent pouchitis in patients with restorative proctocolectomy for ulcerative colitis. Gut 1996;38:362-364.

46. Shen B, Fazio VW, Remzi FH, et al. Risk factors for diseases of ileal pouch-anal anastomosis after restorative proctocolectomy for ulcerative colitis. Clin Gastroenterol Hepatol 2006;4:8189.

47. Gorrepati VS, Stuart A, Deiling S, et al. Smoking and the risk of pouchitis in ulcerative colitis patients with ileal pouch-anal anastomosis. Inflamm Bowel Dis 2018;24:2027-2032.

48. To N, Ford AC, Gracie DJ. Systematic review with meta-analysis: the effect of tobacco smoking on the natural history of ulcerative colitis. Aliment Pharmacol Ther 2016;44:117-126.

49. Achkar JP, Al-Haddad M, Lashner B, et al. Differentiating risk factors for acute and chronic pouchitis. Clin Gastroenterol 
Hepatol 2005;3:60-66.

50. Wu XR, Ashburn J, Remzi FH, Li Y, Fass H, Shen B. Male gender is associated with a high risk for chronic antibiotic-refractory pouchitis and ileal pouch anastomotic sinus. J Gastrointest Surg 2016;20:631-639.

51. Tiainen J, Matikainen M. Long-term clinical outcome and anemia after restorative proctocolectomy for ulcerative colitis. Scand J Gastroenterol 2000;35:1170-1173.

52. Singh S, Sharma PK, Loftus EV Jr, Pardi DS. Meta-analysis: serological markers and the risk of acute and chronic pouchitis. Aliment Pharmacol Ther 2013;37:867-875.

53. Araki T, Hashimoto K, Okita Y, et al. Colonic histological criteria predict development of pouchitis after ileal pouch: anal anastomosis for patients with ulcerative colitis. Dig Surg 2018; 35:138-143.

54. Dipasquale V, Mattioli G, Arrigo S, et al. Pouchitis in pediatric ulcerative colitis: a multicenter study on behalf of Italian Society of Pediatric Gastroenterology, Hepatology and Nutrition. Dig Liver Dis 2019;51:1551-1556.

55. Hurst RD, Molinari M, Chung TP, Rubin M, Michelassi F. Prospective study of the incidence, timing and treatment of pouchitis in 104 consecutive patients after restorative proctocolectomy. Arch Surg 1996;131:497-500.

56. Isaacs KL, Sandler RS, Abreu M, et al. Rifaximin for the treatment of active pouchitis: a randomized, double-blind, placebo-controlled pilot study. Inflamm Bowel Dis 2007;13:12501255.

57. Magro F, Gionchetti P, Eliakim R, et al. Third European evidence-based consensus on diagnosis and management of ulcerative colitis. Part 1: definitions, diagnosis, extra-intestinal manifestations, pregnancy, cancer surveillance, surgery, and ileo-anal pouch disorders. J Crohns Colitis 2017;11:649-670.

58. Shen B, Achkar JP, Lashner BA, et al. A randomized clinical trial of ciprofloxacin and metronidazole to treat acute pouchitis. Inflamm Bowel Dis 2001;7:301-305.

59. Gionchetti P, Rizzello F, Helwig U, et al. Prophylaxis of pouchitis onset with probiotic therapy: a double-blind, placebo-controlled trial. Gastroenterology 2003;124:1202-1209.

60. Mimura T, Rizzello F, Helwig U, et al. Four-week open-label trial of metronidazole and ciprofloxacin for the treatment of recurrent or refractory pouchitis. Aliment Pharmacol Ther 2002;16:909-917.

61. Abdelrazeq AS, Kelly SM, Lund JN, Leveson SH. Rifaximinciprofloxacin combination therapy is effective in chronic active refractory pouchitis. Colorectal Dis 2005;7:182-186.

62. Gionchetti P, Rizzello F, Poggioli G, et al. Oral budesonide in the treatment of chronic refractory pouchitis. Aliment Pharmacol Ther 2007;25:1231-1236.

63. Uchino M, Ikeuchi H, Matsuoka H, et al. Topical tacrolimus therapy for antibiotic-refractory pouchitis. Dis Colon Rectum 2013;56:1166-1173.

64. Gionchetti P, Calabrese C, Calafiore A, et al. Oral beclomethasone dipropionate in chronic refractory pouchitis. J Crohns Colitis 2014;8:649-653.

65. Mimura T, Rizzello F, Helwig U, et al. Once daily high dose probiotic therapy (VSL\#3) for maintaining remission in recurrent or refractory pouchitis. Gut 2004;53:108-114.

66. Gionchetti P, Rizzello F, Venturi A, et al. Oral bacteriotherapy as maintenance treatment in patients with chronic pouchitis: a double-blind, placebo-controlled trial. Gastroenterology 2000;119:305-309.

67. Liu Z, Song H, Shen B. Pouchitis: prevention and treatment. Curr Opin Clin Nutr Metab Care 2014;17:489-495.

68. Ferrante M, D’Haens G, Dewit O, et al. Efficacy of infliximab in refractory pouchitis and Crohn's disease-related complications of the pouch: a Belgian case series. Inflamm Bowel Dis 2010;16:243-249.

69. Barreiro-de Acosta M, García-Bosch O, Souto R, et al. Efficacy of infliximab rescue therapy in patients with chronic refractory pouchitis: a multicenter study. Inflamm Bowel Dis 2012;18: 812-817.

70. Kelly OB, Rosenberg M, Tyler AD, et al. Infliximab to treat refractory inflammation after pelvic pouch surgery for ulcerative colitis. J Crohns Colitis 2016;10:410-417.

71. Uchino M, Ikeuchi H, Bando T, et al. Clinical features of refractory pouchitis with penetrating lesions and the efficacy of infliximab treatment for patients with ulcerative colitis after restorative proctocolectomy. Digestion 2015;92:147-155.

72. Barreiro-de Acosta M, García-Bosch O, Gordillo J, et al. Efficacy of adalimumab rescue therapy in patients with chronic refractory pouchitis previously treated with infliximab: a case series. Eur J Gastroenterol Hepatol 2012;24:756-758.

73. Kjær MD, Qvist N, Nordgaard-Lassen I, Christensen LA, Kjeldsen J. Adalimumab in the treatment of chronic pouchitis: a randomized double-blind, placebo-controlled trial. Scand J Gastroenterol 2019;54:188-193.

74. Segal JP, Ding NS, Worley G, et al. Systematic review with meta-analysis: the management of chronic refractory pouchitis with an evidence-based treatment algorithm. Aliment Pharmacol Ther 2017;45:581-592.

75. Herfarth HH, Long MD, Isaacs KL. Use of biologics in pouchitis: a systematic review. J Clin Gastroenterol 2015;49:647-654. 
76. Huguet M, Pereira B, Goutte M, et al. Systematic review with meta-analysis: anti-TNF therapy in refractory pouchitis and Crohn's disease-like complications of the pouch after ileal pouch-anal anastomosis following colectomy for ulcerative colitis. Inflamm Bowel Dis 2018;24:261-268.

77. Fedyk ER, Wyant T, Yang LL, et al. Exclusive antagonism of the $\alpha 4 \beta 7$ integrin by vedolizumab confirms the gut-selectivity of this pathway in primates. Inflamm Bowel Dis 2012;18:21072119.

78. Bär F, Kühbacher T, Dietrich NA, et al. Vedolizumab in the treatment of chronic, antibiotic-dependent or refractory pouchitis. Aliment Pharmacol Ther 2018;47:581-587.

79. Gregory M, Weaver KN, Hoversten P, et al. Efficacy of vedolizumab for refractory pouchitis of the ileo-anal pouch: results from a multicenter US cohort. Inflamm Bowel Dis 2019;25: 1569-1576.

80. Sandborn WJ, Gasink C, Gao LL, et al. Ustekinumab induction and maintenance therapy in refractory Crohn's disease. N Engl J Med 2012;367:1519-1528.
81. Sands BE, Sandborn WJ, Panaccione R, et al. Ustekinumab as induction and maintenance therapy for ulcerative colitis. N Engl J Med 2019;381:1201-1214.

82. Ollech JE, Rubin DT, Glick L, et al. Ustekinumab is effective for the treatment of chronic antibiotic-refractory pouchitis. Dig Dis Sci 2019;64:3596-3601.

83. Colombel JF, Ricart E, Loftus EV Jr, et al. Management of Crohn's disease of the ileoanal pouch with infliximab. Am J Gastroenterol 2003;98:2239-2244.

84. Shah H, Zezos P. Pouchitis: diagnosis and management. Curr Opin Gastroenterol 2020;36:41-47.

85. Weaver KN, Gregory M, Syal G, et al. Ustekinumab is effective for the treatment of Crohn's disease of the pouch in a multicenter cohort. Inflamm Bowel Dis 2019;25:767-774.

86. Ardalan ZS, Sparrow M, Gibson PR. The importance of accurate phenotyping and pouchitis risk and dietary assessment when investigating the microbial factors behind antibiotic-dependent pouchitis. Gastroenterology 2020;159:399-400. 